\title{
The Midlife Crisis of IT: Accurate Versus Inaccurate Perception of IT Effects
}

\author{
Michael Bayer \\ Technical University of \\ Denmark \\ $\underline{\text { mbay@dtu.dk }}$
}

\author{
Anders Haug \\ University of Southern \\ Denmark \\ adg@sam.sdu.dk
}

\author{
Jolina Lombardi \\ University of Ulm \\ jolina.lombardi@uni- \\ ulm.de
}

\author{
Lars Hvam \\ Technical University of \\ Denmark \\ lahv@dtu.dk
}

\begin{abstract}
Information technology (IT) has been established as a major enabler for business performance. However, studies of the effects of IT typically involve the implicit assumption that the effects reported by the companies studied adequately and accurately describe IT's effects. In this paper, we challenge this perspective by arguing that in many cases the perceived and actual effects of IT are different. Although most IT researchers likely recognize the discrepancy, this topic has not received much attention. Thus, through a case at a world-leading logistics company, we provide evidence that perceived and actual effects of IT can differ. On this basis, we develop a set of models that describe such discrepancies and use theories from the psychological literature to explain why the discrepancies occur. In this context, we use the term "midlife crisis" as a metaphor for what happens to decision makers' perception of IT systems after a period of use.
\end{abstract}

\section{Introduction}

The term "midlife crisis" was coined by Elliott Jaques [1] in the 1965 paper "Death and the Mid-life Crisis." The term describes a psychological crisis somewhere in the middle of life (around 45 to 55 years old by today's standards) caused by events that highlight aspects such as increasing age, mortality, and lack of accomplishments in life [2]. This crisis can lead to depression, remorse, and high anxiety levels, as well as a desire to achieve youthfulness and drastically change one's current lifestyle. Although modern researchers have questioned the generalness, and even the existence, of this phenomenon, the term is frequently applied to label the behavior of middle-aged people facing depression or making radical changes in their lifestyles [2]. What does this have to do with information technology (IT)? Not much directly, but as we argue in this paper, "midlife crisis" is a very suitable metaphor for what happens to decision makers' perception of IT systems after a period of use in organizations.

Research interest in the business value of IT has increased rapidly, not least since the work in 1990s, promising major gains from the use of IT [3], [4]. Since then, IT has been established as a major enabler of business performance [5]. The stream of literature focusing on the effects of IT in companies is sometimes referred to as to as "IT business value" (ITBV) [5]. Melville et al. [6] (2004) proposed a definition for ITBV: "the organizational performance impacts of IT at both the intermediate process level and the organization-wide level and comprising both efficiency impacts and competitive impact."

However, the beneficial effects of IT have been the subject of much debate. Specifically, early IT studies often indicated that despite the clear potential of IT for producing productivity gains, in many cases these gains were not achieved or only to a limited extent [7]. This gave rise to the term "IT productivity paradox," as well as more research on the business value of IT [8]. In this context, more recent studies commonly reported a significant positive effect of IT on productivity [9], [10], [11], as well as on other performance measures [12], [13]. ITBV research has mainly focused on tangible financial measures, which, however, do not capture the many intangible benefits of IT [14].

Even if limiting the focus to the tangible benefits of IT, there may still be a discrepancy between perceptions of the ITBV within a particular organization and the actual ITBV. Although most ITBV researchers likely recognize this discrepancy, the topic has not received much attention in the ITBV literature. Furthermore, ITBV studies typically involve the implicit assumption that the effects reported by the companies studied adequately and accurately describe the actual effects of IT. In this paper, we challenge this perspective by arguing that in many cases the perceived and actual effects of IT are different. Specifically, through a case study of IT projects at a world-leading transportation and logistics service provider, we provide evidence that perceived and actual effects of IT can be different. On this basis, we 
develop a set of models that describe such discrepancies and use theories from the psychological literature to explain why the discrepancies occur.

The remainder of this paper is organized as follows. First, Section 2 provides a brief review of literature related to ITBV. Next, Section 3 outlines the research method. Hereafter, Section 4 describes the case study context and the key findings from the case study. In Section 5, we analyze these results and develop a set of models, describing the discrepancies between perceived and actual IT system performance. Section 6 then explains these relationships using the psychological literature. The paper ends with a discussion of the implications and limitations of this study in Section 7.

\section{Theoretical background}

Some of first research on ITBV was conducted by King and Schrems [15], who focused on efficiency gains at the company level. They classified benefits as follows: (1) "benefits from contributions of calculating and printing tasks," (2) "benefits from contributions to record-keeping tasks," (3) "benefits from contributions to record-searching tasks," (4) "benefits from contributions to system restructuring capability," (5) "benefits from contributions of analysis and simulation capability," and (6) "benefits from contributions to process and resource control." Such benefits are, obviously, influenced by the IT in those days that was mainly used for transactional purposes.

Later, based on Turner and Lucas's [16] work, Weill [17] developed a framework that resonated better with the current uses of IT. Specifically, they classified IT investments according to three main organizational objectives: strategic, informational, and transactional. These categories were later operationalized by Mirani and Lederer [18], who, through a review of the IT literature, populated each of the three ITBV categories with 33 explicit benefits. Through an analysis of these benefits, the authors developed a questionnaire and tested it on IS professionals, giving rise to the final set of dimensions and items of organizational benefits of IT. Later, Gregor et al. [19] tested this classification and added a dimension, "transformational benefits," based on Brynjolfsson and Hitt's [20] work. This dimension concerns employee skill-level improvement, new business plans, expansion of organizational capabilities, business model improvement, and organizational structure or process improvement [19].

As statistical evidence of ITBV became increasingly common, the focus in the literature changed to how value is created by IT [21], although the exact measurement remains controversial [5]. In the literature, there is agreement that IT does not per se create value, only when combined with complementary resources, not the least human and business processes [21], [22]. A consequence of this perspective is a focus on effectively integrating IT into organizational structures, and thus, much recent ITBV literature has emphasized the complementary factors influencing IT's effectiveness. These factors include business process engineering [23], job training [24], and management [25], [26]. Therefore, research on complementary factors contributes to better understanding of how to improve the return of IT investment.

As stated in the Introduction, there may be a discrepancy between the perceptions of the effects of IT systems in an organization and the actual effects of these systems. This topic has not received much attention in the literature. However, ITBV studies typically involve the assumption that effects reported by companies studied accurately describe the actual effects of IT. We argue (and later explore in a case study) that IT systems in some cases go through what may be described as a midlife crisis in the form of a decline in managers' appreciation. A midlife crisis describes a dissatisfaction with the previous and current life situation, which can lead a person to make radical lifestyle changes in an attempt to escape from this kind of feeling. Such radical changes, however, often do not produce the desired outcomes. Thus, in most cases, it is more beneficial to work with the problems at hand rather than inducing radical changes. The same goes for IT managers. Rather than investing in new IT in an attempt to escape problems or unfulfilled expectations related to existing IT systems (or merely a desire for something new), often it would be more beneficial to focus on investigating and solving the issues related to the experienced problems or unfulfilled expectations of the existing systems. Focusing on the problems that led to dissatisfaction, rather than investing in new IT systems, may be more constructive in handling such an "IT midlife crisis", as it may improve return on IT investment and avoid unnecessary IT replacement decisions.

Nevertheless, in some cases, the decrease in the appreciation of an IT system is warranted, that is, if an IT system's performance is actually declining. Such a decline can have several explanations, including license agreements cannot be renewed, vendors no longer support the software, newer software is emerging in the market, or new business strategies require other functionality [27], [28]. However, in some cases, the arguments for implementing new IT systems are not warranted by an actual lack of IT system effect. The decisions to discard or replace an IT system are the product of a decision maker's 
perception, which may be more or less accurate. We explored this phenomenon through a case study.

\section{Methodology}

To investigate the research question, we chose a single in-depth case study approach. This choice was made as case studies allow for the study of a phenomenon in its real-life context, thus facilitating a rich dialogue between theory and the evidence [29]. The case study was conducted at a world-leading transportation and logistics service provider. Because of the requirement of anonymity, the company is referred to as TransCo in this paper.

TransCo operates in more than 80 countries with more than 60,000 employees worldwide. Due to today's highly complex and global supply chains, as well as customers' strict time, quality, and price requirements, TransCo relies heavily on IT to manage the information flows. The strong IT support for TransCo's operations can be described by a portfolio of multiple thousands of IT applications and by a ninefigure IT budget (in euros). TransCo has grown in recent years mostly through mergers and acquisitions (M\&As). To standardize operations and maintain operational efficiency, TransCo opts for global and standardized IT systems across countries. TransCo is one of the major players in a highly fragmented industry, and the company has a proven track record when it comes to IT integration and IT implementations, as this is key for successful M\&As while maintaining smooth operations. Thus, TransCo provides a rich source of data for investigating IT implementation and IT value projects.

To investigate whether there is a misconception between actual and perceived IT effects, as well as the potential consequences of such misperceptions, we decided to investigate this phenomenon at one of TransCo's major IT systems. We refer to this IT system as a transportation management system (TMS), and it is a system that is implemented in 67 countries. The TMS hosts more than 12,000 users every week and up to 7,500 concurrently working users in the IT system.

Productivity data per country were gathered from the central enterprise resource planning ERP system for all 67 countries that work with the TMS. The first productivity data were collected for January 2015 and were gathered aggregated per month. Productivity in this context is considered shipments per operational full-time employee (FTE), which comprises freight forwarders.

During this period (January 2015 to December 2019), 18 implementations of the TMS took place, which serve as the core of this case study. Additionally, the measurements of the IT effect were complemented by informal and formal interviews. During the informal interviews, notes were taken to document events and attitudes in relation to the project.

The formal interviews focused on gathering the perceptions of the IT effect of the TMS. These interviews were conducted by the first author of this paper through semi-structured interviews with four key informants. Interviewee A was the senior director of IT governance, the voice of the senior IT executive team and their perception of the TMS. To gather another holistic perception, interviewee $\mathrm{B}$ was a business architect. Interviewee $\mathrm{C}$ was a project manager responsible for implementing the TMS, and interviewee $\mathrm{D}$ was a senior manager and previously, a specialist for the TMS. The interviews are audiorecorded, and key phrases were transcribed.

\section{Case study results \\ 4.1. Case study context}

The TMS is an end-to-end IT system and supports the entire core process of one of TransCo's core divisions, referred to as Division A. The TMS is a freight-forwarding system that supports and optimizes the entire business process from capacity planning and rate management to the booking of the carrier.

As each country reports per division, and Division A's core process is supported by only the TMS, it can be argued that it is a fair assumption to understand the effect of the TMS on the individual country's performance in isolation. Thus, with the implementation of the TMS, certain performance improvements should be seen after a period of time in each country.

In the case of the TMS, productivity gains, as well as an overall IT cost reduction, were expected due to the one standardized IT system across all countries. The researchers chose 18 countries where the TMS was recently implemented as a baseline for the actual IT effects. All 18 countries used an IT system before the TMS implementation; thus, the productivity gains were not expected to be dramatic. Nevertheless, the previous IT systems were perceived as inferior.

Productivity was measured in all countries as shipments registered in the IT systems per operational FTE. As TransCo had implemented the TMS multiple times, experience showed that visible IT effects should manifest around three months after the implementation. Therefore, we measured the actual IT effect of the TMS implementation per country by examining the productivity data nine months before and after implementation. The nine-month periods before and after implementation were chosen to account for 
seasonal fluctuations (comparing the same month before and after implementation), as well as complications during implementation, which could have delayed the actual IT effects.

\subsection{General understanding of the IT effect}

To have a baseline when comparing actual and perceived IT effects, a general understanding of the actual IT effect during the lifecycle of an IT system is needed. Based on the measurements of the TMS project's effects, as well as the observations, conversations, and interviews about experiences of other IT system rollouts, four distinct project phases can be defined: implementation phase (Phase A), optimization phase (Phase B), optimum phase (Phase C), and decline phase (Phase D). Figure 1 depicts a generic illustration of the TransCo IT projects, where the actual phases of individual IT rollouts deviate from the parameters $t_{a}, t_{b}, t_{c}, t_{d}$, and $m_{\text {effect }}$ and are supported by quotes from interviewees.

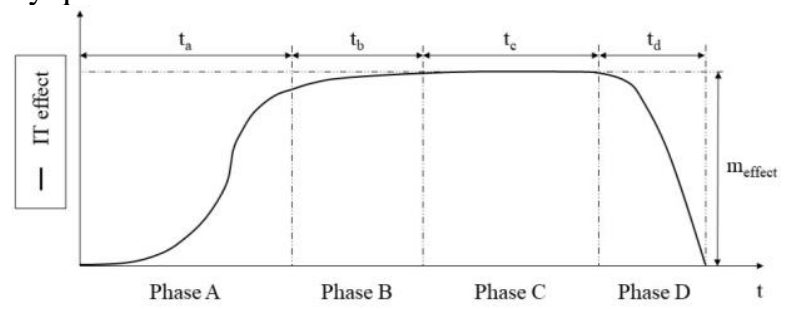

Figure 1. General understanding of the IT effect lifecycle

4.2.1. Phase A. With the rollout of an IT system, different IT effects are expected, such as productivity and/or revenue improvements, (IT) cost reduction, or transparency improvements. The IT effect depends on which business process the IT system is implemented in at TransCo. Phase $\mathrm{A}$ is the implementation phase, when the IT system is implemented, and initial staff training takes place before the go-live date to acquaint staff with the new IT system. Therefore, when going live, the IT projects at TransCo typically showed a strong increase in the IT effect due to the initial staff training. The implementation time could vary due to "the issue of poor implementation or adoption or training" according to the enterprise architect. This is supported by the senior manager's statement that country X "did not really train themselves a lot before their go-live, which resulted in more questions after." Furthermore, the project manager emphasized the importance of the country managers' engagement and referred to another rollout, where they were "very strong in the change management of people [...] and that made it so smooth." Therefore, the time period of Phase A, namely, parameter $t_{a}$ as well as parameter $m_{\text {effect }}$ may vary due to these factors. Consequently, "with a proper implementation, you can actually gain more from the IT system," the senior director emphasized.

4.2.2. Phase B. Whereas a significant increase in the IT effect is typically seen with and after the go-live event of an IT system, in the following months and years the curve of the IT effect flattens. Although the IT effect increase from the new IT implementation is not as significant in Phase B compared to that in Phase A, through fine-tuning and optimizing the current way of working, there are still additional IT effects to harvest. Through gradual learning, users "utilize the tool better" and thus, harvest more of the IT investment, the senior director said. Therefore, additional staff training and frequent use of the IT implementation typically lead to optimization of the operations and thus, to additional IT effect gains seen at TransCo.

4.2.3. Phase C. Depending on staff training, their learning capabilities, etc., a certain level of IT effect is reached. During previous IT rollouts at TransCo, it could be observed that the curve of the IT effect at some point remained stable and fluctuated only slightly around the maximum. Therefore, the trajectory in Phase $\mathrm{C}$ is slightly concave and is distinct from the ascending trajectory in the optimization phase. Nevertheless, the optimum (maximum $m_{\text {effect }}$ ) is not the maximum effect of an IT system; instead, the optimum resembles the maximum an organization or country achieves and depends on the previously described factors. The senior manager stated that "some countries are better than others, we know that. And we can link that to, let's say, the number of support requests they raise and the types of requests they raise." Last, optimal operations last as long as there are no changes in the business process, information flow, surrounding IT system as well as the IT system itself, represented by parameter $t_{c}$ in Figure 1.

4.2.4. Phase D. Finally, the study showed that at some point, the effect of an IT system decreases. This typically occurs when a business process changes or at the (technical) end of the lifecycle of an IT system. Therefore, given that "IT is a tool to make sure that business runs well, [...] but it only supports business," then with the changing business setup the support function of IT is reduced. Thus, in such cases, a decline in the IT effect was typically experienced at TransCo.

\subsection{Perceived versus actual IT effects}

The overall perception of the effects of the TMS at TransCo can be described with quotes from the 
interviewees, such as "there is nothing better out there in the market" and "based on our analysis and experience so far, there is really no alternative to the vastness of [the TMS] as a whole application." The enterprise architect stated that "from a business point of view, they are extremely happy with it. I have not heard any complaints or somebody that are even discussing [that they] want to change away from [the TMS]." Furthermore, when the interviewees compared the TMS to previous IT systems, they rated the TMS superior. This was confirmed when the researcher specifically asked about the effect of the TMS compared to one of the previous IT systems, called the TMS_old. The senior manager responded that "the functionality available [in the TMS] does not compare to [the TMS_old] at all." In addition, the TMS_old had been tailored to support another division's core process, referred to Division $\mathrm{B}$, and thus, he added that "it could never work in a global setting [for Division A's core process], and the amount of functionality, it's like comparing New York to a small [...] city with 500 people." Following, the TMS is definitely superior compared to the TMS_old for Division A's core process.

In contrast, the results for the actual IT effect of the TMS indicated, compared to the positive perceptions of the persons involved in the project, that only one third of the 18 countries had achieved productivity gains within the first nine months after implementation, whereas the remaining two-thirds showed neutral or negative productivity developments. Especially the TMS after implementation in three countries where the TMS_old was implemented, did not show any productivity gains in any country.

When asked for especially good or bad perceived IT rollouts per country, the project manager pointed out one bad country, where frustration with the rollout was immense. In this country, the go-live date was delayed by 1.5 years, which can be linked to the lack of a joint-venture agreement. Furthermore, after the agreement was finally sorted out, the staff initially trained 1.5 years before on the TMS had been decreased due to the IT implementation delay, and new staff without training in the TMS had been hired. Therefore, an upward trend in productivity could be slowly expected 1.5 years after the project started according to the project manager.

When the actual effects in this country were examined, there was an increase in productivity after 1.5 years. Furthermore, the productivity exceeded the average productivity of the previous IT system.

Another question posed to all interviewees was whether they believed that there was a difference in productivity levels in Phase $\mathrm{C}$ across countries with the same standard IT system. Two interviewees perceived that there were certainly differences in productivity across countries, but the other two interviewees assumed that due to the standardized IT system and business process, there should not be much room to diverge. The project manager stated, "In general, globally, I would say that it is kind of the same productivity level."

To compare the effects of the TMS, we selected 49 countries where the TMS was rolled out before 2015, assuming that each country had reached its individual optimum, namely, Phase C. Calculating the average productivity per country for 2018 and 2019, we discovered a relative standard deviation across the 49 countries of $35 \%$ and $29 \%$ for 2018 and 2019, respectively.

\section{Case study analysis 5.1. Inaccurate perception of the effectiveness of the IT system}

Comparing the perceived effectiveness of the TMS to the actual numbers indicated a misperception. Specifically, the four respondents stated that the TMS performed well and that it was superior to the previous IT systems, although this was not the case. This misperception of the TMS was an overestimation of the TMS's effectiveness (Figure 2). Stretching this thought a bit further, this could mean that such misperceptions can be one explanation for why the question about the value of IT is still a prominent debate in the IT literature.

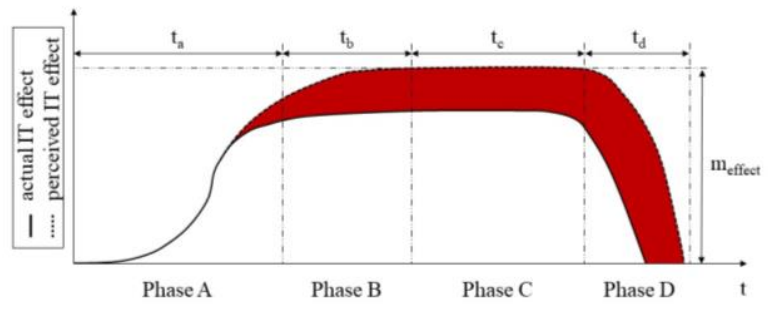

Figure 2. Inaccurate perception (overestimation)

\subsection{Inaccurate perception of the effectiveness of "old" IT systems}

The senior manager clearly stated that the TMS was superior to the TMS_old in terms of functionality and business process support, as the TMS_old was tailored to Division B's core process instead of Division A's. Although the reason for replacing the TMS_old with the TMS was to drive standardization across Division A, the senior manager perceived the TMS as superior in functionality. Nevertheless, when all three countries that used the TMS_old before the TMS were compared, no superiority was visible in the actual 
productivity numbers. Instead, the actual numbers indicated one negative and two neutral productivity developments compared to the previous IT system.

The TMS_old was the standardized IT system for the core process of Division B and will be replaced by a new IT system in 2021. The enterprise architect stated that the reason for replacement at Division B "is not a functionality issue, that they are addressing it, they changing the platform to mitigate technology issues because the platform of [the TMS_old] is outdated."

The replacement of the TMS_old through the TMS in Division A started in the three countries in January 2016, but the TMS_old will be first replaced divisionwide across Division B in 2021 due to an outdated platform. We suggest that premature IT replacements may be seen as suboptimal from the perspective of the return on IT assets. Therefore, knowing that the TMS has been rolled out since 2016 in more than dozen countries, it could have been economically wiser to first replace the previous IT systems with the TMS in those countries, where the functionality or the IT system is outdated. This could also explain why the senior manager rated the TMS_old in the current state as inferior to the TMS. However, looking into the actual numbers, after the rollout in January 2016, no productivity gains were visible, as the TMS_old may have been in Phase $\mathrm{C}$ when it operated at its optimum. Therefore, potential underestimations of the IT effect of "old" IT systems should be avoided, especially when the "old" IT system may be operating at its optimum (Figure 3). This may be another explanation for the question about the value of IT. The IT effect life cycle might be shortened due to premature IT replacements. Thus, the return on IT investments may be lower than they potentially could be.

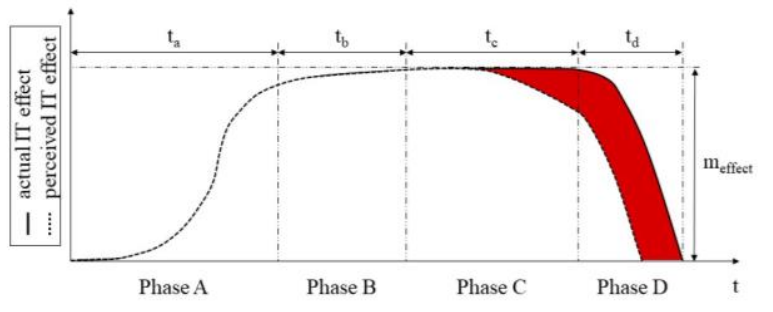

Figure 3. Inaccurate perception (underestimation)

\subsection{Accurate perception of underperformance of the IT implementation}

The perception of the project manager, when asked for an example of difficulty with the IT implementation, was consistent with the actual low productivity level in this country. The project manager confirmed that they relied solely on their experience and perception: "We don't measure it. It is a perception [whether the IT system is well implemented and adopted], but we look at the people and say how does it work." Although the TMS had been implemented and the staff had been trained, the project manager did not end the project, as she foresaw complications due to the go-live delay. A misperception of the IT implementation, and thus, Phase A, would have delayed the IT effect of the TMS even further because the majority of staff was newly hired without training in the TMS. The project manager's perception was in line with the actual numbers, and this project had not ended prematurely. In the case of the premature end of a project, the senior manager described a likely scenario: "If they do not have sufficient knowledge in [the TMS] and experience, which, you can track it back to implementation, you can track it back to various things, then they are not working as smart as they could. And when they are not working as smart as they could, they have a tougher time bringing new business in to be handled by the same number of people and then they would have to hire more." This means reaching the maximum would take the country much longer compared to the other countries. Figure 4 shows the "lost potential" in the IT effect in the case of misperception.

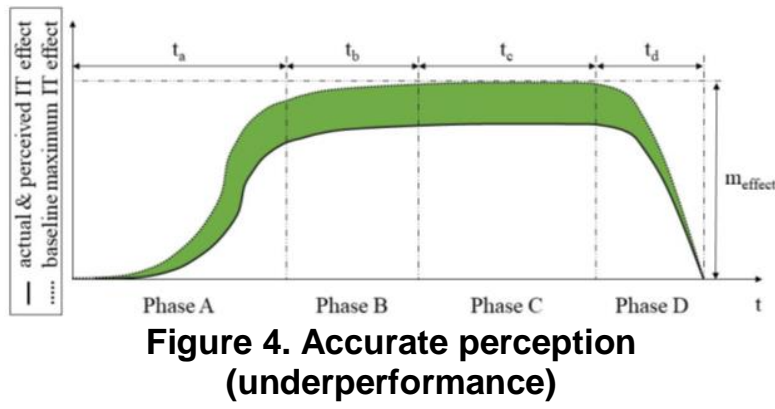

\section{4. (In)accurate perception of varying degrees of IT effect across countries}

The interviewees' perceptions of the varying degrees of the IT effect of the IT system across countries differed. The actual numbers of the 49 reference countries, which had worked with the TMS for more than five years, and thus, should have reached their optimum, indicated a large difference in productivity levels across countries. This result contradicts the senior executive's and the project manager's perceptions despite the standardized IT system and business process across the countries. The enterprise architect stated that "if other countries can show that they can produce more with less, and that is the trend, and then if single countries cannot, then there must be something wrong, not only with the IT implementation but also with the business setup." This 
can be one explanation for the varying levels of productivity across the countries and builds on the previously discussed underperformance of IT implementations. A misperception of nonexistent productivity variations would oversee "lost potential" and thus, would not exploit the full potential of an IT investment (Figure 4). In contrast, in the case where the interviewees' perceptions of the varying productivity levels were in line with the actual numbers, such accurate perceptions can trigger, for example, additional staff trainings or lessons learned from the "high performing" implementations, to harvest the IT system's remaining potential.

\subsection{Accurate versus inaccurate perception of IT effect}

Based on the case analysis, a two-by-two matrix was derived (Figure 5), where the x-axis displays the perception and $y$-axis the actual IT effect. This also served as cross-analysis of whether an obvious case was overlooked. Accurate perceptions of high IT effect were not explicitly mentioned at TransCo. We argue that achieving a high IT effect is the reason for every IT implementation, and typically, only extreme cases are memorable. The accurate perception of a high IT effect is reasonable in TransCo's case, given the generally positive attitude toward the TMS and the actual six positive implementations of the TMS with productivity gains compared to the previous IT systems. Therefore, Figure 5 may serve as a classification for various scenarios between perceived and actual IT effects.

\begin{tabular}{l|c|c|}
\multicolumn{1}{c}{} & \multicolumn{1}{c}{$\begin{array}{c}\text { Accurate } \\
\text { perception }\end{array}$} & \multicolumn{1}{c}{$\begin{array}{c}\text { Inaccurate } \\
\text { perception }\end{array}$} \\
\cline { 2 - 3 } $\begin{array}{l}\text { Actual high } \\
\text { IT effect }\end{array}$ & $\begin{array}{c}\text { Accurate } \\
\text { estimation of } \\
\text { high IT effect }\end{array}$ & $\begin{array}{c}\text { Underestimation } \\
\text { of IT effect }\end{array}$ \\
Actual low & Accurate & \\
IT effect & $\begin{array}{c}\text { Overestimation } \\
\text { of IT effect }\end{array}$ \\
\cline { 2 - 3 } & IT effect & \\
\hline
\end{tabular}

Figure 5. Perceived vs. actual IT effect

\section{Discussion}

\subsection{Lifecycle of IT effect as a baseline}

The typically observed trajectory of the IT effect of a successful IT implementation with its four phases (Figure 1), based on actual measurements and experiences at TransCo, was used to compare perceived and actual IT effects, as well as for better sense-making of the findings. However, parameters (i.e., $t_{a}, t_{b}, t_{c}, t_{d}$, and $m_{\text {effect }}$ ) had to be included as obviously every IT implementation, although the IT system was the same, may show different behavior. Therefore, we connect the four phases and the parameters observed at TransCo to the literature.

In Phase A (the implementation phase), a drastic increase in IT effect was experienced at TransCo after the go-live event. This can be explained by the common view within the IT literature that IT is a tool and per se, does not create value, only in combination with complementary resources [21], [22]. This means that as soon as the (IT) tool is used in the go-live event, the purpose of the (IT) tool unfolds and results in an effect, the IT effect. Furthermore, the time for harvesting the majority of the IT effect by actually making use of the (IT) tool's purpose varies and was linked to "the issue of poor implementation or adoption or training" at TransCo. This is in line with the literature. Many researchers have investigated socalled contextual factors, such as job training [24], business process engineering [23], and management [26], that influence the effectiveness of IT systems. This means that organizations with superior IT implementation abilities achieve superior firm performance [30], [31]. Therefore, the form of the curve in Phase A and its potential variances, indicated by parameter $t_{a}$, are dependent on contextual factors, as well as the organization's IT capabilities.

The observed slowdown in the increase in the effect of IT, while still in an incline, during Phase B (Figure 1) was explained at TransCo by the continuously improved utilization of the IT system. Devaraj and Kohli [32], for example, found statistical evidence that the actual use of IT, meaning the frequency, has a performance impact. Furthermore, firms with higher IT use achieve generally higher performance gains [33]. Thus, the slow incline observed at TransCo in Phase B can be explained by optimization of the way of working due to extensive IT use. Therefore, parameters $m_{\text {effect }}$ and $t_{b}$ in Figure 1 depend on IT use.

Phase $\mathrm{C}$ was derived from stagnation in the IT effect after a certain period at TransCo. This was seen as the optimum of utilizing the effect of IT. We argue that it is natural that everything reaches its maximum at some point. However, the maximum IT effect measured for an IT implementation is not necessarily 
the maximum potential of an IT system. This can be explained by the factors that affect IT effectiveness.

After optimal utilization of IT, and thus, the maximum IT effect, naturally, a declining phase occurs. This can be explained by Furneaux and Wade's [34] findings that, typically, shortcomings in IT system capability, support, and technical integration are the reasons for the intention to replace an IT system. The decline may be stepwise rather than that depicted in Figure 1.

\subsection{Psychological reasons for inaccurate perceptions of IT effects}

Making decisions is part of everyday life, and especially important in progressive business development. Under ideal conditions, the human mind would work according to the so-called homo oeconomicus depicting a decision maker led solely by rationality, relentlessly determined by hierarchical prioritization, and primarily driven by utility maximization [35]. However, aside from intrinsic factors, like preferences, expectations, emotions, or even information processing strategies that affect one's decision making, extrinsic circumstances, such as lack of sufficient time and either too much or too little information, often impede making the best of all choices. To function efficiently under such limited conditions, decision making often relies on heuristics that are, in general, useful but may also lead to systematic incorrect propensities in perception, memory, and judgment, called cognitive biases [36].

According to this concept, one may identify different role models in this case study relying on various information and starting points thus explaining the diverse perceptions of the implementation and execution of TransCo's new TMS system: The most preferable scenario displays a congruent relation between the situation's valuation and its actual outcome (accurate perception). If the IT effect is accurately perceived, adequate decisions can be made, for example, as the project manager did when postponing the premature ending of the implementation phase (an accurate estimation of low IT performance). Likewise, sites with smooth implementation phases due to sufficiently trained staff who are capable of developing during the transitional strategy and meeting the expected productivity imply adequate judgment (an accurate estimation of high IT performance). In each case, accurate perception of either high or low IT performance presupposes that circumstances are judged rationally, evidence-based, and locational.

In less favorable cases, however, judgment does not consider actual impact factors sufficiently (inaccurate perception): Not only exaggerated expectations but also the so-called pro-innovation bias [37] may cause discounted aspects. In addition to mere overvaluation of usefulness versus an underrated grasp of limitations concerning innovations, the premature replacement of current economically efficient systems may occur (underestimation of IT performance). Additionally, inaccurate perception in terms of unequivocal success expectancy may be due to principles following the availability heuristic that labels an assumption based on "the ease with which instances or occurrences can be brought to mind" [36]. Successful implementations in terms of uneventful transitions may be more prominent than those falling behind first expectations thus biasing present and future changeover processes and country-individual adjustments. In addition, high anticipation generated by successful transitions may generate the phenomenon of anchoring bias [36]. In other words, an anticipated aim (the successful implementation of the TMS and its causative increase in productivity) that was initially set would not be adjusted properly in relation to confounding factors, so that outcome expectations were placed recklessly in relation to the initial expectancy (overestimation of IT performance).

\section{Implications, limitations, and concluding remarks}

We first argued that the concept of midlife crisis could be used as a metaphor to describe the relation between decision makers and IT systems. As shown by the case study, at some point in an IT system's life cycle, decision makers believe something should happen to their IT system or its infrastructure. Sometimes, such beliefs are warranted, as existing systems have low effects, compared to possible alternatives. However, in other cases, bringing in new IT systems would lead only to decreases in efficiency as well as lower the return on prior IT investments.

This paper has two main theoretical implications. First, this paper addresses a rarely investigated research perspective on the value of IT, namely, the possible misperception of the effectiveness of an IT implementation, which we examined as a single indepth case study. Two types of inaccuracy in perception, over- and underestimation of the IT effect, were identified. Such managers' misperceptions may obviously lead to inadequate decision, which are based on an inappropriate interpretation of reality. The second contribution of this paper is the explanation for the misperceptions. The difference between the perceived and actual IT effects can be explained by managers' cognitive bias. Cognitive bias is an 
extensive research area; however, it was applied in this context as an attempt to explain the misperception of IT effect and thus, in a wider context adding to the discussion about the value of IT. This means that applying a psychological lens in this context could be an attempt to explain the still popular question about the value of IT. This could be explained by cognitive bias of some decision makers, who either tend to prematurely replace valuable IT (reducing return on IT investment) or overestimate the IT effect and thus, cannot live up to promises.

The practical implications of this paper concern raising awareness that actual and perceived IT effects can diverge. This, in turn, means that managers may make inadequate decisions based on inaccurate interpretations. Therefore, the two-by-two matrix (Figure 5) could be one way to help organizations classify their IT projects accordingly and react accordingly. This means, for example, that a perceived low performance should be measured before taking any measurements. In the case of actual low performance, the described contextual factors should be considered for better implementation or adoption of the IT system and thus, harvesting the full potential of the IT investment. In the case of a misperception, meaning that the actual IT effect is high but perceived as low, unnecessary IT replacements can be avoided. In contrast, when the perception of IT effectiveness is high, but the actual effect is low, then managers should initiate further investigations to discover whether the reasons for the actual underperformance are insufficiencies during implementation or optimization, whether the IT system is at the end of life cycle (Phase D) or whether the IT effect was simply overpromised. Needless to say, when perceived and actual IT effects are high, then managers can move their resources and attention to projects where it is actually needed.

Limitations of this research are the single case study and may pose doubts in terms of generalizability in the statistical sense. Nevertheless, generalizability of the findings are discussed in a theoretical way by linking the findings to previous research. Furthermore, perception is by nature subjective, and if different interviewees had been chosen, they likely would have provided different answers. Nevertheless, the purpose of this paper was not to determine specific characteristics of managers that point toward specific cognitive biases. Instead, this research aims to shed light on the difference between actual and perceived IT effects, and thus, we strongly advocate for more factbased decision making. Therefore, future researcher should investigate the severity of such a misperception, to quantify the "lost potential" of the IT effect with misjudgment of performance as over- and underestimated. Furthermore, this research only confirms the necessity of previous and current research efforts to improve accuracy in measuring the IT effect, be it tangible or intangible, by improving the understanding of the differential IT effect. Last, as measuring everything is difficult, future research should investigate specific characteristics, whether personal traits or the relation of the employee to the IT project, which may indicate managers' perceptions of an IT project. Thus, based on such advances in understanding, priority could be given to IT projects to establish measurements first, where based on judging the perception in relation to specific traits could indicate severe misperceptions.

\section{References}

[1] E. Jacques, "Death and the Mid-life Crisis", International Journal of Psycho-Analysis, 1965, pp. 502-514.

[2] A.M. Freund and J.O. Ritter, "Midlife Crisis: A Debate", Gerontology, 2009, pp. 582-591.

[3] T.H. Davenport, Process Innovation: Reengineering Work Through Information Technology," Harvard Business Press, Boston, 1993.

[4] M.M. Hammer and J.A. Champy, Reengineering the Corporation: Manifesto for Business Revolution. HarperBusiness, New York, 1993.

[5] F. Wiengarten, P. Humphreys, G. Cao, and M. McHugh, "Exploring the Important Role of Organizational Factors in IT Business Value: Taking a Contingency Perspective on the Resource-Based View", International Journal of Management Reviews, 2013, pp. 30-46.

[6] N. Melville, K. Kraemer, and V. Gurbaxani, "Review: Information Technology and Organizational Performance: An Integrative Model of IT Business Value”, MIS Quarterly, 2004, pp. 283-322.

[7] G. P. Hackett, "Investment in Technology - The Service Sector Sinkhole?", Sloan Management Review, 1990, pp. 97-103.

[8] E. Brynjolfsson, "The Productivity Paradox of Information Technology", Communications of the ACM, 1993, pp. 66-77.

[9] T.A. Byrd, E.H. Thrasher, T. Lang, and N.W. Davidson, "A Process-Oriented Perspective of IS Success: Examining the Impact of IS on Operational Cost", Omega, 2006, pp. 448-460.

[10] Y.C. Chou, H.H.-C. Chuang, and B.B.M. Shao, "The Impacts of Information Technology on Total Factor Productivity: A Look at Externalities and Innovations", International Journal of Production Economics, 2014, pp. 290-299.

[11] J. Dedrick, V. Gurbaxani, and K.L. Kraemer, "Information Technology and Economic Performance: A Critical Review of the Empirical Evidence", ACM Computing Surveys, 2003, pp. 1-28.

[12] T.S. Hong and M. Ghobakhloo, "IT Investments and Product Development Effectiveness: Iranian SBs", Industrial Management \& Data Systems, 2013, pp. 265293. 
[13] M.J. Meixell, "Quantifying the Value of Web Services in Supplier Networks", Industrial Management \& Data Systems, 2006, pp. 407-422.

[14] S. Daulatkar and P.S. Sangle, "Proposed ReConceptualization of IT Business Value Benefits", Business Process Management Journal, 2016, pp. 522-545.

[15] J.L. King and E.L. Schrems, "Cost-benefit Analysis in Information Systems Development and Operation", Computing Surveys, 1978, pp. 19-34.

[16] J. Turner and H. Lucas, "Developing Strategic Information Systems", W. Guth (Ed.), Handbook of Business Strategy, Warren, Gorham and Lamont, Boston, 1984, pp. 1-36.

[17] P. Weill, "The Relationship Between Investment in Information Technology and Firm Performance: A Study of the Valve Manufacturing Sector", Information System Research, 1992, pp. 307-333.

[18] R. Mirani and A.L. Lederer, "An Instrument for Assessing the Organizational Benefits of IS Projects", Decision Science, 1998, pp. 803-838.

[19] S. Gregor, M. Martin, W. Fernandez, S. Stern, and M. Vitale, "The Transformational Dimension in the Realization of Business Value From Information Technology", The Journal of Strategic Information Systems, 2006, pp. 249-270.

[20] E. Brynjolfsson and L.M. Hitt, "Beyond Computation: Information Technology, Organizational Transformation and Business Performance", Journal of Economic Perspectives, 2000, pp. 23-48.

[21] A. Neumeier, T. Wolf, G. Fridgen, H.-V. Müller, and C. Reith, "Natural and Design Science Perspective on the Business Value of IT", Americas Conference on Information Systems, 2017, p. 1-10.

[22] T.-P. Liang, J.-J. You, and C.-C. Liu, "A ResourceBased Perspective on Information Technology and Firm Performance: A Meta-Analysis", Industrial Management \& Data Systems, 2010, pp. 1138-1158.

[23] K. Altinkemer, Y. Ozcelik, and Z.D. Ozdemir, "Productivity and Performance Effects of Business Process Reengineering: A Firm-Level Analysis", Journal of Management Information Systems, 2001, pp. 129-162.

[24] G. Barczak, F. Sultan, and E.J. Hultink, "Determinants of IT Usage and New Product Performance", Journal of Product Innovation Management, 2007, pp. 600613.

[25] A. Khayer, Y. Bao, and B. Nguyen, "Understanding Cloud Computing Success and Its Impact on Firm Performance: An Integrated Approach", Industrial Management \& Data Systems, 2020, pp. 963-985.

[26] F. Lai, X. Zhao, and Q. Wang, "The Impact of Information Technology on the Competitive Advantage of Logistics Firms in China", Industrial Management \& Data Systems, 2006, pp. 1249-1271.

[27] M. Bradley and R.J. Dawson, "An Analysis of Obsolescence Risk in IT Systems", Software Quality Journal, 1998, pp. 123-130.

[28] P. Sandborn, "Software Obsolescence - Complicating the Part and Technology Obsolescence Management
Problem", IEEE Transactions on Components and Packaging Technologies, 2007, pp. 886-888.

[29] R.K. Yin, R.K. Case Study Research: Design and Methods, Sage Publications, Los Angeles, 2009.

[30] A. S. Bharawaj, "A Resource-Based Perspective on Information Technology Capability and Firm Performance: An Empirical Investigation", MIS Quarterly, 2000, pp. 169-196.

[31] S. Mishra, S. B. Modi and A. Animesh, "The Relationship between Information Technology Capability, Inventory Efficiency, and Shareholder Wealth: A Firm-Level Empirical Analysis”, Journal of Operations Management, 2013, pp. 298-312.

[32] S. Devaraj and R. Kohli, "Performance Impacts of Information Technology: Is Actual Usage the Missing Link?", Management Science, 2003, pp. 273-289.

[33] M. Reid, E.J. Hultink, T. Marion, and G. Barczak, "The Impact of the Frequency of Usage of IT Artifacts on Predevelopment Performance in the NPD Process", Information \& Management, 2016, pp. 422-434.

[34] B. Furneaux and M. Wade, "An Exploration of Organizational Level Information Discontinuance Intentions", MIS Quarterly, 2011, pp. 573-598.

[35] W. Bongard, "Der Wirtschaftsmensch (homo oeconomicus) Dogmenhistorischer Abriß." Nationalökonomie, wohin?. VS Verlag für Sozialwissenschaften, Wiesbaden, pp. 24-31, 1965.

[36] D. Kahneman, P. Slovic, and A. Tversky, Judgment Under Uncertainty: Heuristics and Biases. Cambridge University Press, Boston, 1982.

[37] E. Rogers, Diffusion of Innovations, 5th ed., The Free Press, New York, 2003. 